\title{
Low plasma iron status and akathisia
}

\author{
A Barton, J Bowie, K Ebmeier
}

\begin{abstract}
Thirty patients were examined to test the hypothesis that a depletion of iron levels is associated with symptoms of akathisia. Fifteen akathisic patients were pair-matched with 15 non-akathisic patients. Plasma ferritin levels were significantly decreased in the akathisic patients, and there was a significant inverse correlation between plasma iron levels and akathisia rating. In addition, akathisia ratings were found to be correlated with a scale measuring symptoms of tardive dyskinesia.
\end{abstract}

A previous study conducted in Glasgow ${ }^{1}$ reported significantly lower serum iron and percentage saturation and a higher total iron binding capacity in a group of chronic psychiatric patients with akathisia compared with matched controls. The authors also found a (non significant) correlation of $-\mathbf{0 . 4 2}$ (Spearman's rho) between serum iron and akathisia rating. After the exclusion of an outlying value, there were no significant differences in ferritin levels between groups. The authors argued that akathisia might therefore be related to dopamine-D2 receptor hypofunction due to a relative deficit of serum and consequently brain iron. They suggested that, like the restless leg syndrome, akathisia might be amenable to iron supplement treatment. We felt that a replication study should be carried out for the following reasons: apart from the possibility of a false positive result due to small numbers $(n=13)$ and certain methodological shortcomings discussed below, the reported profile of results is not plausible: if akathisic patients were suffering from relative iron depletion, a decrease in ferritin levels should have occurred before a reduction of serum iron levels. ${ }^{2}$ In addition, akathisia remains a common side effect of neuroleptic medication which might not only decrease compliance or lead to diagnostic difficulties, ${ }^{1}$ but in chronic patient groups represents an unwelcome stigma. The lack of effective therapeutic options for the syndrome warrants a thorough search for predisposing factors and rationales for alternative treatments of akathisia.

\section{Patients and methods}

Fifteen akathisic patients were recruited from acute and long stay wards in the Royal Cornhill and Kingseat Hospitals, Aberdeen.
They were pair-matched with 15 patients by age, sex, length of illness, length of recent inpatient stay, and dose of neuroleptic medication. Patients on iron supplements, on nonsteroid anti-inflammatory drugs, on antacids, and cimetidine were excluded. Since the hypothesis was based on a presumptive interactive effect of neuroleptic medication and iron at the receptor level, patients receiving the atypical neuroleptic oxypertine ${ }^{3}$ were excluded from the study. Pre-menopausal females and patients with clinical or laboratory evidence of renal or hepatic failure, as well as patients with a history of organic brain damage and epilepsy were excluded.

All patients were treated with neuroleptic drugs with no change in dose over the previous month. The number of cigarettes smoked per day was recorded. Patients were assessed by two raters independently, using the Brief Psychiatric Rating Scale, ${ }^{4}$ the Hamilton Anxiety Scale, ${ }^{5}$ the Simpson and Angus Scale for drug induced Parkinsonism, ${ }^{6}$ the Abnormal Involuntary Movement Scale (AIMS), ${ }^{7}$ and an Akathisia Scale used in the previous study. ${ }^{1}$ Venous blood samples $(40 \mathrm{ml})$ were collected between 7 and 8 am on two consecutive days following an overnight fast and before breakfast. Samples were taken without tourniquet in the sitting position and collected in heparinised vacutainers. Samples were immediately separated using an MSE bench centrifuge at $3000 \mathrm{~g}$ for 10 minutes, then divided into $1 \mathrm{ml}$ aliquots, frozen and stored at $-20^{\circ} \mathrm{C}$ in plastic tubes until analysed. The analyses were performed in a single batch blind procedure. Per assay and patient, four samples were analysed, that is, two split-half samples for each of the two consecutive days. The assay procedures for plasma iron, transferrin-binding, and ferritin have been described in detail elsewhere. ${ }^{8}$ Data were analysed using the Aberdeen University mainframe computer and SPSSX. ${ }^{9}$ Ethical approval for the study was given by the Joint Ethical Committee of Grampian Health Board and the University of Aberdeen. Informed consent was obtained from all subjects.

\section{Results}

Means and standard deviations for the matching variables for akathisics and controls are given in table 1. There were no significant differences between groups for these variables. There was also no difference in the number of cigarettes smoked by patients in either group. The inter-rater reliability of 
Table 1 Patient characteristics, Means (SE)

\begin{tabular}{lcc}
\hline & Controls & Akathisics \\
\hline $\begin{array}{l}\text { Sex (Female:Male) } \\
\text { Age (years) }\end{array}$ & $5: 10$ & $5: 10$ \\
$\begin{array}{l}\text { Duration of illness } \\
\text { (years) }\end{array}$ & $51.8(3 \cdot 4)$ & $51.5(3 \cdot 4)$ \\
$\begin{array}{l}\text { Duration of treatment } \\
\text { (years) }\end{array}$ & $24 \cdot 4(3 \cdot 2)$ & $27.8(3 \cdot 9)$ \\
$\begin{array}{l}\text { Dose of medication in } \\
\text { chlorpromazine units }\end{array}$ & $16 \cdot 1(4 \cdot 4)$ & $18 \cdot 5(4 \cdot 8)$ \\
per day & $999 \cdot 0(336 \cdot 2)$ & $942.5(426 \cdot 0)$ \\
\hline
\end{tabular}

total movement disorder scores was acceptable, with $95 \%$ confidence intervals for interrater differences within $+/-2$ scoring points. There was no systematic relationship between inter-rater differences and average scores. ${ }^{10}$ Average scores of both raters could therefore be used. Median scores and ranges of rating scales for akathisics and controls are given in table 2. Significant differences between groups were only found for the AIMS ( $p=$ 0.002 , Wilcoxon test) and the Akathisia Scale $(\mathrm{p}=0.0007$, Wilcoxon test). The coefficients of variation $(100 \times$ standard deviation $\div$ mean) for repeat measures of each of the iron status parameters were close to or below previously reported or manufacturer's data. ${ }^{8}$ Values for iron, transferrin, and percentage saturation of transferrin were low, but within the normal range. The same was true for ferritin in the control group. Ferritin levels in the group of akathisic patients were below normal with a mean of $39.35+/-6.97 \mathrm{ng} / \mathrm{ml}$. Full blood counts were normal in all patients, as were urea, electrolytes and liver function tests.

Multiple analyses of variance were carried out with the iron status parameters as depen- dent variables. A repeated measures design was used with the within-subjects factors of group (akathisic versus non-akathisic), day (first or second), and split-half of sample (first or second). The effect of akathisia versus control was significant $(p=0.024)$ for serum ferritin only. No other single or interaction effect was significant for any of the other dependent variables. Figure 1 gives the average values for patients plotted in pairs. There was a significant product moment correlation coefficient of $\mathrm{r}=-0.49(\mathrm{df}=13$, $\mathrm{p}=0.03$ ) between Akathisia score and plasma iron in the akathisic group (fig 2).

There was also a significant correlation between AIMS scores and akathisia scores $(\mathrm{df}=$ $28, p \leqslant 0.01)$. The closest fit $\left(R^{2}=0.56\right)$ was achieved by a quadratic regression equation: AIMS-Score $=1.5+0.3 \times$ Akathisia Score $+0.01 \times$ (Akathisia Score ${ }^{2}$ ). Akathisia scores were not correlated with dose of neuroleptic, with drug-induced Parkinsonism, or with anxiety scores.

To achieve greater comparability between studies, the result of pairs with an akathisic patient with akathisia scores $>10(n=11)$ were analysed separately. ${ }^{1}$ The result of the MANOVA was similar to that for the whole group, with a significant group-effect (akathisic versus non-akathisic) for ferritin-levels $(p=0.008)$. The inverse correlation between plasma iron levels and akathisia scores in the akathisic group increased and therefore remained significant even for the smaller number $(r=-0.55, d f=9, p=0.04)$.

While Brown et al excluded patients with tardive dyskinesia and Parkinsonian symptoms, the patients in this study showed a range of severities for both syndromes (table
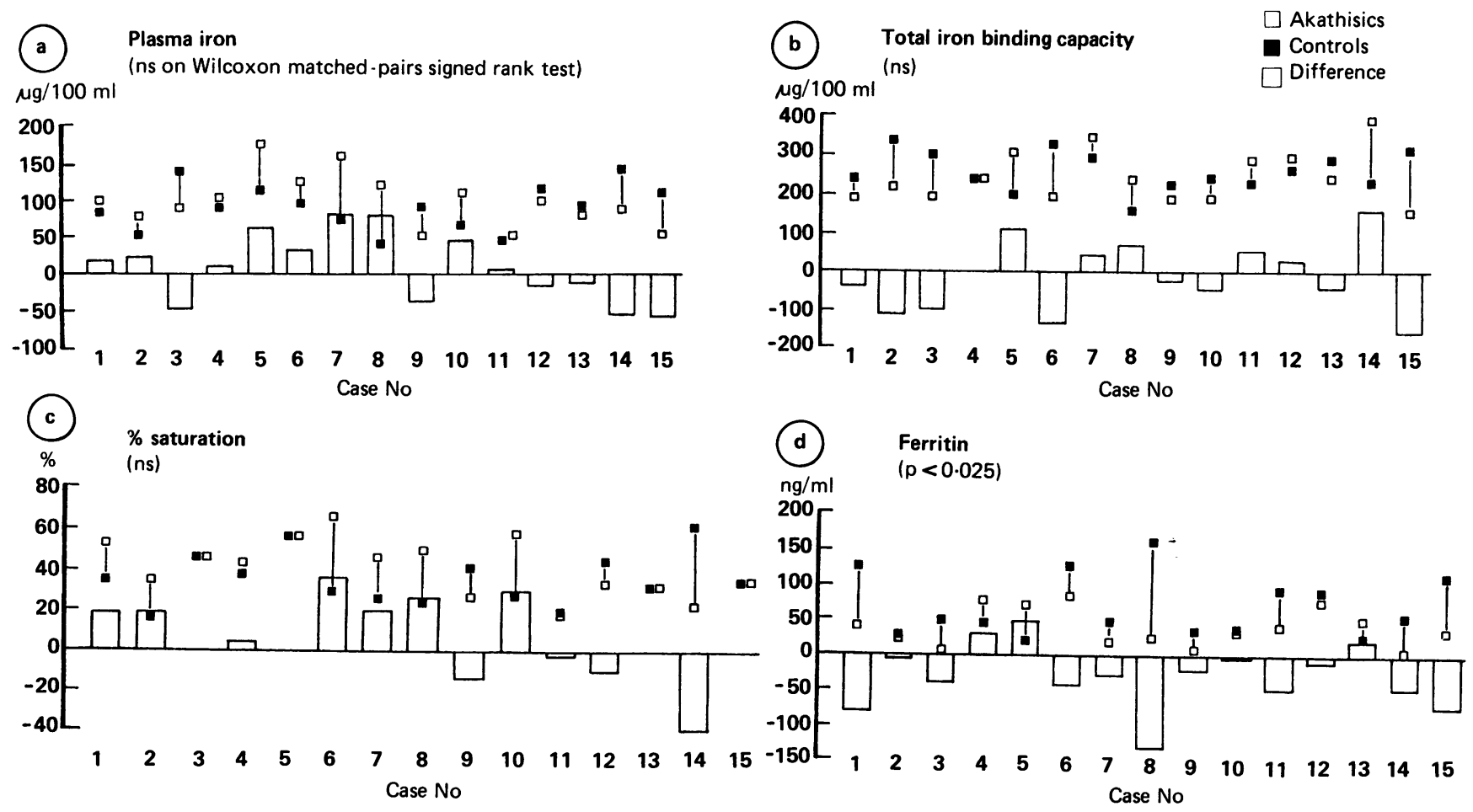

Figure 1 Iron parameters in matched pairs. 


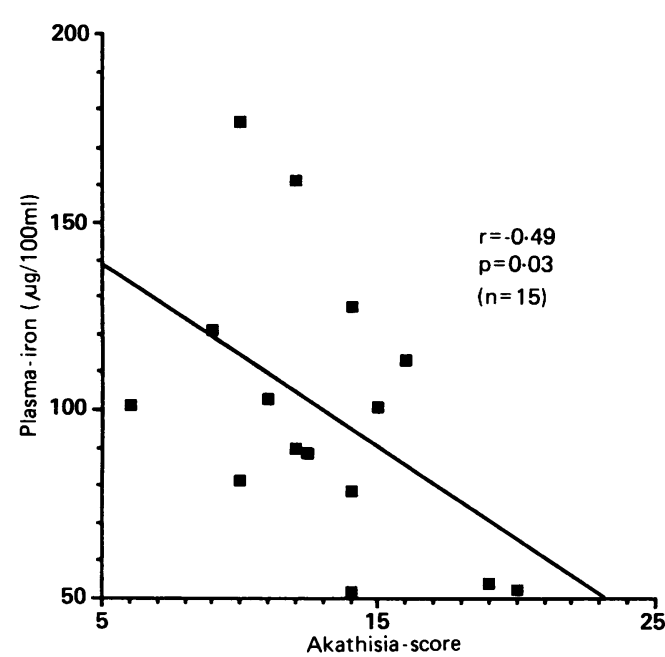

Figure 2 Correlation between plasma iron and akathisia score.

1). If the patients with "probable tardive dyskinesia" "11 (AIMS score $>2$ ) and Parkinsonian symptoms ${ }^{6}$ (Simpson and Angus score $>3$ ) were excluded, none of the patients with akathisia and only six of the controls remained.

\section{Discussion}

This study broadly supports the notion that chronic akathisia in patients on long term neuroleptic treatment may be related to the depletion of iron stores. This is suggested by the significant reduction of plasma-ferritin levels in the akathisic group. ${ }^{2}$ We were also able to replicate the finding of a correlation between akathisia scores and iron levels. The care given in this study to the standardisation of blood sampling and to an assessment of the reliability of measures, together with the results of the previous study, ${ }^{1}$ suggest that these findings are valid. As described by Brown et al, ${ }^{1}$ dietary iron depletion has been found to mimic D-2 receptor blockade in a variety of animal models. In addition, iron depletion has been shown to lead to a reversible reduction of $B_{\max }$ for ${ }^{3} \mathrm{H}$-Spiperone binding in caudate nucleus. ${ }^{12}$ This would give a rationale for a causal explanation of the symptoms of akathisia by low iron levels.

We feel that the situation might be more complicated, as the patients examined in the two studies did not appear to have acute akathisia which occurs when neuroleptic medication is started or increased, but chronic "tardive" akathisia. ${ }^{13}$ Our patients, as well as those of Brown's, were on doses of neuroleptic

Table 2 Rating scale parameters

\begin{tabular}{|c|c|c|c|c|}
\hline & \multicolumn{2}{|c|}{ Controls $(n=15)$} & \multicolumn{2}{|c|}{ Akathisics ( $n=15$ ) } \\
\hline & Median & Range & Median & Range \\
\hline $\begin{array}{l}\text { Brief psychiatric rating scale } \\
\text { Hamilton anxiety scale } \\
\text { Simpson and Angus scale }\end{array}$ & $\begin{array}{r}21 \\
1 \\
4\end{array}$ & $\begin{array}{l}3-35 \\
0-10 \\
0-15\end{array}$ & $\begin{array}{r}24 \\
3 \\
6\end{array}$ & $\begin{array}{r}16-33 \\
0-13 \\
0-13\end{array}$ \\
\hline $\begin{array}{l}\text { Abnormal involuntary movement } \\
\text { scale }\end{array}$ & 1 & $0-3$ & 7 & $\begin{array}{l}1-16 \\
6-20\end{array}$ \\
\hline
\end{tabular}

drugs which had been unchanged for at least one month. Although patients with Parkinsonism and tardive dyskinesia had been excluded by Brown et al, no exclusion criteria or rating scale data were supplied. ${ }^{1}$ We found that symptoms of akathisia in our patient group (which was very similar in the composition of age, length of illness and treatment to the patients in the study by Brown et al) were related to symptoms of tardive dyskinesia measured by the AIMS. Indeed, it proved impossible to find akathisic chronic psychiatric patients who scored within the normal range of both the AIMS and the Simpson and Angus scale for Parkinsonian symptoms.

A possible relationship between iron and tardive dyskinesia has also recently been suggested by Yehuda and Youdim. ${ }^{12}$ Chronic treatment of rats with haloperidol not only prevents the development of D2-receptor subsensitivity induced by nutritional iron depletion, but also reverses these changes if given afterwards. ${ }^{14}$ It appears that neuroleptic drugs can lead to a redistribution of body iron with an accumulation in certain structures of the brain..$^{16}$ Iron accumulation, in turn, leads to dopamine receptor supersensitivity, as can be shown by intracranial injection of iron. ${ }^{17} 18$ Alternatively, and possibly in addition to the previous mechanisms, the catalytic effect of iron accumulated in globus pallidus and substantia nigra ${ }^{1516}$ on $\mathrm{H}_{2} \mathrm{O}_{2}$ generated by enzymatic reactions in the basal ganglia could lead to the generation of free radicals and to lipid peroxidation of nigro-pallidal and striato-nigral GABA systems. ${ }^{19}$ This could be responsible for the irreversible brain damage associated with some cases of tardive dyskinesia.

Some aspects of the above hypothesis are directly amenable to empirical testing in patients: for example, an examination of the relationship between iron status and tardive dyskinesia in patients would be of interest. The effect of neuroleptic medication on iron parameters during acute treatment, and its relationship with acute akathisia should be examined in a prospective study.

Finally, the time appears to be ripe for a controlled study of iron supplement treatment in chronic akathisia, although the failure to increase brain iron levels in rats by intravenous infusion of oxyferriscorbone ${ }^{20}$ is likely to temper excessive optimism.

1 Brown KW, Glen SE, White T. Low Serum Iron Status and Akathisia. Lancet 1987;i:1234-6.

2 Herbert E. Recommended dietary intake of iron in humans. Am J Clin Nutr 1987;45:680.

3 Palomo T, Russel PA, Ebmeier KP, Salzen EA, Ashcroft GW. Effect of oxypertine versus haloperidol on apomorphine induced activity in rats. Proc IUPHAR 9th Internat Congr Pharmacol (London) 1984.

4 Overall J, Gorham D. Brief Psychiatric Rating Scale. Psychological Reports 1962;10:799-812.

5 Hamilton $M$. Diagnosis and rating of anxiety. In: Lader MH, ed. Studies of Anxiety. Br J Psychiat 1969; ( Special Publication) 3:76-9.

6 Simpson G, Angus J. A rating scale for extrapyramidal side effects. Acta Psychiat Scand 1970;(Suppl 212):11-9.

7 NIMH. Abnormal Involuntary Movement Scale. In: ECDEU assessment manual for psychopharmacology. ECDE assessment manual for psychopharmacology:
United States: DHEW, Rockville, 1976:ADH 76-338: 534-7. 
8 Barton AC. Plasma iron and trace element status in neuroleptic induced akathisia. MSc Thesis, University of Aberdeen, 1988.

9 Norusis MJ. SPSSX Advanced Statistics Guide. New York: McGraw-Hill, 1985.

10 Bland J, Altman D. Statistical Methods for assessing agreement between two methods of clinical measurement. Lancet 1986;i:307-10.

11 Schooler NR, Kane JM. Research diagnoses for tardive dyskinesia. Arch Gen Psychiatry 1982;39:486-7.

12 Yehuda S, Youdim MBH. Brain iron deficiency: Biochemistry and behaviour. In: Youdim MBH, ed. Topics in neurochemistry and neuropharmacology Vol 2. London: Taylor and Francis, 1988.

13 Barnes T, Braude W. Akathisia variants and tardive dyskinesia. Arch Gen Psychiatry 1985;42:874-78.

14 Ben-Shachar D, Youdim MBH. Neuroleptic induced dopamine receptor supersensitivity and tardive dyskinesia may involve altered iron metabolism. Br J Pharmacol
1987;90:95.

15 Campbell WG, Raskind MA, Gordon T, Shaw CM. Iron pigment in the brain of a man with tardive dyskinesia. $A m$ J Psychiat 1985;142:364-5.

16 Hunter R, Blackwood W, Smith MC. Neuropathological findings in three cases of persistent dyskinesia following phenothiazine medication. J Neurol Sci 1968;7:263-73.

17 Csernansky JG, Holman CA, Bonnet KA, Grabowsky K, King R, Hollister LE. Dopaminergic supersensitivity at distant sites following induced epileptic foci. Life Sci 1983;32:385-90.

18 Ben-Shachar D, Jacobowitz D, Youdim MBH. Dopamine D2 receptor modulation by brain non-haem iron. Br J D2 receptor modula

19 Cadet JL, Lohr JB, Jeste DV. Free radicals and tardive dyskinesia. Trends Neurosci 1986;9:107-9.

20 Dexter DT, Jenner P, Marsden CD. Oxyferriscorbone elevates the total iron content of blood but not brain. Movement Disorders 1989;4:176-82.

\section{A note on Jacob Augustus Lockhart Clarke}

I have in another brief communication summarised the prodigious anatomical and clinical investigations of Lockhart Clarke whose name is known to students of medicine as the originator of the description of the nucleus intermediolateralis and column of grey matter in the spinal cord. His personal history is not without interest.

He was born in London in 1817, but was educated in France until the age of 13 . He followed his grandfather and brother into medicine, studying at Guy's and St Thomas' hospitals. It appears he did not graduate at the University of London, but was made a Licentiate of the Society of Apothecaries in 1842 and entered general practice. Clarke was a retiring, quiet and modest man described by contemporaries as "of noble independence, honest and just and intellectually keen". He later recommenced his studies at St George's and became MRCS (Eng) in 1860.

Clarke lived with his mother in Pimlico, and it was here that he engaged in his meticulous anatomical studies of the spinal cord and brain. He used spirits of wine and turpentine as fixatives. He distinguished the lateral from the medial cuneate (or "restiform") nucleus, and identified the nucleus intermediolateralis and the "posterior vesicular column"' now known as Clarke's column. He experimented with techniques for preserving histological sections and devised the trick of mounting them in balsam.

He provided an early account of syringomyelia and also published clinical papers on hysterical paroxysms, epilepsy, and the treatment of neuralgias by iodine. His anatomical researches were chronicled in a remarkable number of papers in the Philosophical Transactions of the Royal Society and other distinguished journals. However, recognition evaded him until he was made an FRS in 1854 and in 1864 was awarded their gold medal. In 1867 he was elected an honorary Fellow of the King's and Queen's College of Physicians in Ireland. Ironically it was only after obtaining a degree from St Andrews in
1869 that he was elected MRCP after examination. The Censors' Board resolved:

"to recommend him to the College for admission to Examination under the dispensing Clause". Permission was granted by Comitia on 24 July 1871 (annals RCP, vol 30: $p$ 186) and he was examined on the Practice of Medicine, The Principles of Public Health, and Psychological Medicine and approved on 26 July (p 192). He was elected member by Comitia on 27 July (p 193). The 'Dispensing Clause in his case was probably clause XVI of the ByeLaws.' On the Practice of Medicine, etc was one of two written papers; it appears he was excused 'On Medical Anatomy and on the Principles of Medicine' which three of the other four candidates had to sit at that time. When and where any of them confronted the three viva voce examinations required under clause XIV is not mentioned.

It reflects more on the Royal College than on Clarke that he was not made a Fellow: his name does not appear in Munk's roll. He left general practice in 1870-71 and was appointed to the Hospital for Epilepsy and Paralysis where he worked with a small private practice and little other income until his death. He suffered a severe attack of pleurisy in 1870 and in 1879 his health gradually failed. He was attended in his last illness by Hughlings Jackson and Stephen Mackenzie. The Medical Times and Gazette, 31 January 1880 (p 138) records: "Many friends would have been glad of the privilege of serving him, but he was, though kind hearted and generous, very reserved, and few knew of his illness. He passed away quietly in the first hour of 25 January, 1880."

1 Clarke JAL. Researches into the structure of the Spinal Cord (1850). Philos Trans Roy Soc London 1851;141:607-22. 2 Pearce JMS. A note on the work of Clarke of Clarke's Column. J Neurol Neurosurg Psychiatry 1990; (in press).

I am indebted to Mr Alan J Clark, Librarian at the Royal Society and to $\mathrm{Mr}$ Geoffrey Davenport, Librarian at the Royal College of Physicians for biographical data and references.

JMS PEARCE 